\title{
Iodine uptake, storage and translocation mechanisms in spinach (Spinacia oleracea L.)
}

\author{
O. S. Humphrey - S. D. Young • E. H. Bailey - N. M. J. Crout • E. L. Ander • \\ E. M. Hamilton • M. J. Watts
}

Received: 12 July 2018/ Accepted: 26 February 2019

(C) Springer Nature B.V. 2019

\begin{abstract}
Iodine is an essential micronutrient for human health; phytofortification is a means of improving humans' nutritional iodine status. However, knowledge of iodine uptake and translocation in plants remains limited. In this paper, plant uptake mechanisms were assessed in short-term experiments (24 h) using labelled radioisotopes; the speciation of iodine present in apoplastic and symplastic root solutions was determined by (HPLC)-ICP-QQQ-MS. Iodine storage was investigated in spinach (Spinacia oleracea L.) treated with $\mathrm{I}^{-}$and $\mathrm{IO}_{3}{ }^{-}$. Finally, translocation through the phloem to younger leaves was also investigated using a radioiodine $\left({ }^{129} \mathrm{I}^{-}\right)$label. During uptake, spinach roots demonstrated the ability to reduce $\mathrm{IO}_{3}{ }^{-}$to $\mathrm{I}^{-}$. Once absorbed, iodine was present as org-I or $\mathrm{I}^{-}$with significantly greater concentrations in the apoplast than the symplast. Plants were shown to absorb similar concentrations of iodine applied as $\mathrm{I}^{-}$or $\mathrm{IO}_{3}{ }^{-}$, via the roots, grown in an
\end{abstract}

\footnotetext{
O. S. Humphrey · E. L. Ander · E. M. Hamilton ·

M. J. Watts $(\square)$

Inorganic Geochemistry, Centre for Environmental

Geochemistry, British Geological Survey, Keyworth,

Nottingham NG12 5GG, UK

e-mail: mwatts@bgs.ac.uk

O. S. Humphrey - S. D. Young · E. H. Bailey ·

N. M. J. Crout

School of Biosciences, University of Nottingham, Sutton

Bonington Campus, Loughborough, Leicestershire

LE12 5RD, UK
}

inert growth substrate. We found that whilst leaves were capable of absorbing radioactively labelled iodine applied to a single leaf, less than $2 \%$ was transferred through the phloem to younger leaves. In this paper, we show that iodine uptake is predominantly passive (approximately two-thirds of total uptake); however, $\mathrm{I}^{-}$can be absorbed actively through the symplast. Spinach leaves can absorb iodine via foliar fertilisation, but translocation is severely limited. As such, foliar application is unlikely to significantly increase the iodine content, via phloem translocation, of fruits, grains or tubers.

Keywords Foliar fertilisation - Inhibitor - Iodine . Spinach (Spinacia oleracea L.) · Translocation . Uptake mechanisms

\section{Introduction}

Approximately one-third of the world's population has inadequate iodine consumption, despite the concerted effort of international organisations including World Iodine Association, Iodine Global Network, World Health Organization and United Nations Children's Fund to improve global iodine nutritional status (Andersson et al. 2012; Zimmermann 2008). Iodine is an essential micronutrient for mammalian life involved in production of the thyroid hormones: 
thyroxine and triiodothyronine. Insufficient intake results in a spectrum of clinical and social issues, including goitre, stillbirth, mental impairment and congenital hypothyroidism; collectively known as iodine deficiency disorders (IDD) (Yang et al. 2007; Fuge and Johnson 2015; Gonzali et al. 2017; Zimmermann et al. 2015). The recommended daily dietary intake of iodine varies between 90 and $250 \mu \mathrm{g}$ for children, adults and pregnant/lactating women (WHO et al. 2007; Zimmermann and Andersson 2012). Dietary supplementation, by means of iodised salt, is the most widely used prophylaxis for reducing the prevalence of IDD; however, it has significant drawbacks (Andersson et al. 2012; Mackowiak and Grossl 1999; Zhang et al. 2000). Despite the success of iodised salt programmes in reducing the incidence of severe IDD, inadequate access to fortified salt, the instability of iodine during processing and storage, and the limited monitoring of iodine input to salt all impede the effectiveness of this strategy (Andersson et al. 2012; Gonzali et al. 2017; Cakmak et al. 2017). Consequently, IDD still exists at an epidemic level and resolving this problem demands additional iodine delivery programmes (Medrano-Macias et al. 2016; Lyons 2018).

Phytofortification is an alternative strategy that could complement and strengthen traditional iodine enrichment schemes, particularly as iodine is stable and easily assimilated when bound in food (Lawson et al. 2015; Landini et al. 2011; Weng et al. 2009; White and Broadley 2009; Hong et al. 2009). Previous studies have demonstrated that root vegetables, leafy plants and fruit-bearing crops have the ability to accumulate iodine, proportionate to the amount supplied in the growth substrate (0-20 mg kg-1), with favourably influences on yield (Zhu et al. 2003; Mackowiak and Grossl 1999; Blasco et al. 2008; Dai et al. 2006; Cakmak et al. 2017). However, high concentrations of iodine $\left(>50 \mathrm{mg} \mathrm{kg}^{-1}\right.$ ) are phytotoxic (Medrano-Macias et al. 2016; Weng et al. 2008). Whilst soil fertilisation can increase iodine concentrations in plants, soil properties, including $\mathrm{pH}$, organic matter content, clay minerals and $\mathrm{Al} / \mathrm{Fe} / \mathrm{Mn}$ oxides, significantly influence the speciation and availability of iodine to plants, thereby affecting fertilisation efficacy (Shetaya et al. 2012; Humphrey et al. 2018).

Phytofortification, via foliar fertilisation, is a sustainable and productive crop management technique which is beneficial when (i) soil conditions limit nutrient availability, (ii) soils exhibit high loss rates and (iii) plant physiological factors impair the delivery of nutrients (Fernandez and Brown 2013). Therefore, foliar fertilisation could be a suitable method for iodine fortification, as iodine added to soils undergoes rapid fixation into less available forms, thus limiting uptake (Xu et al. 2011; Keppler et al. 2003). Whilst previous investigations into foliar fertilisation and iodine phloem mobility suggested that little or no iodine translocation occurs in Oryza sativa L. and Phaseolus vulgaris var. Tendergreen (Mackowiak and Grossl 1999; Muramatsu and Yoshida 1995; Tsukada et al. 2008; Herrett et al. 1962), recent foliar fertilisation experiments with Medicago sativa L., Solanum lycopersicum L., Lactuca sativa cv. 'Melodion', Brassica oleracea L. var. gongylodes L. 'Lech', Raphanus sativus L. var. sativus cv. 'Raxe', and grain crops including Oryza sativa, Triticum aestivum and Zea mays, suggest greater phloem mobility than previously reported; as such, further investigation is required (Altınok et al. 2003; Lawson et al. 2015; Smoleń et al. 2014; Landini et al. 2011; Cakmak et al. 2017).

Specific iodine uptake mechanisms have received very little attention at a physiological and molecular level (Gonzali et al. 2017). It has previously been hypothesised that iodine uptake could occur through the apoplastic (extracellular/passive) and symplastic (cytoplasmic/active) pathways within the root. Despite the uncertainty of uptake mechanisms, it is well known that transport is largely xylematic (Herrett et al. 1962; Mackowiak and Grossl 1999; Blasco et al. 2008). Aspecific carriers/channels and specific transporters may exist, but their presence in root cells remains unconfirmed (Medrano-Macias et al. 2016; White and Broadley 2009). Kato et al. (2013) demonstrated that iodate $\left(\mathrm{IO}_{3}{ }^{-}\right)$was converted to iodide $\left(\mathrm{I}^{-}\right)$ in the presence of roots in a hydroponic solution. This conversion suggests that plant roots biologically reduce $\mathrm{IO}_{3}{ }^{-}$to $\mathrm{I}^{-}$; however, it may have been a result of $\mathrm{IO}_{3}{ }^{-}$being an alternate receptor for $\mathrm{NO}_{3}^{-}$reductases (Medrano-Macias et al. 2016). Further clarification of iodine metabolism in plants and soil-to-plant transfer would greatly improve understanding of iodine biogeochemistry.

The aim of this study was to identify and clarify plant-iodine interactions. The objectives were: (i) to assess iodine uptake pathways, using ${ }^{129} \mathrm{I}$ as a label, 
through analysis of apoplastic and symplastic root extracts; (ii) to investigate iodine storage when a treatment solution was applied to an inert growth substrate as iodide $\left(\mathrm{I}^{-}\right)$or iodate $\left(\mathrm{IO}_{3}{ }^{-}\right)$; (iii) to investigate translocation mechanisms through the phloem using foliar application of ${ }^{129}$ I-labelled solutions.

\section{Materials and methods}

\section{Plant material}

Spinach (Spinacia oleracea L.) was selected as a test species in this study as it has previously been identified as a viable choice for iodine phytofortification (Dai et al. 2006). Plants were grown in the experimental glasshouses at the University of Nottingham, Sutton Bonington Campus, UK. Throughout the experiments, plants were watered daily with a nutrient-spiked (HortiMix Standard: $15-7-30+1.6 \mathrm{MgO}+$ Trace Elements (2:1:4)) water solution.

Iodine uptake mechanisms in spinach

Spinach seeds were germinated in cell seedling starter trays filled with moist sand and routinely watered. At 28 days after planting (DAP), individual seedlings were removed from the growth substrate, rinsed with DI water and then washed in Milli-Q water (18.2 M $\Omega$ $\mathrm{cm}$; Millipore) three times. The seedlings were then exposed to a treatment solution, containing ${ }^{129} \mathrm{I}^{-}$and ${ }^{127} \mathrm{IO}_{3}{ }^{-}$at either 100 or $200 \mu \mathrm{g} \mathrm{l}{ }^{-1}$, for $24 \mathrm{~h}$, in the presence and absence of a metabolic inhibitor to help determine uptake pathways: each treatment had three replicates (40 root tips constituted as one sample). The metabolic inhibitor, carbonyl cyanide m-chlorophenyl hydrazine (CCCP), causes an uncoupling of the proton gradient that is established during the normal activity of electron carriers in the electron transport chain and reduces the ability of ATP synthase to function optimally (Ito et al. 1983). The inhibitor effectively reduces the efficiency of uptake in the symplast, as uptake via the symplast requires cellular energy. $\mathrm{CCCP}$ was diluted to $1 \times 10^{-5} \mathrm{M}$ in water from a stock solution of $1 \times 10^{-2} \mathrm{M}$ in ethanol (Wright and Oparka 1997). After exposure to the treatment solution, apoplastic and symplastic root solutions were extracted by centrifugation, using a modified method outlined in Yu et al. (1999) and Mitani and Ma (2005). Briefly, root tips $(0-2 \mathrm{~cm})$ were excised from the seedlings, washed three times in Milli-Q water, blotted dry and placed cut surface down into a Spin-X centrifuge tube with a $0.22-\mu \mathrm{m}$ cellulose acetate filter. To extract the apoplastic solution, roots were centrifuged at $2000 \mathrm{~g}$ for $15 \mathrm{~min}$. The apoplastic solution was then removed, and the root tips were frozen at $-20{ }^{\circ} \mathrm{C}$ for $24 \mathrm{~h}$; once thawed at room temperature, the symplastic solution was extracted by centrifuging at $2000 \mathrm{~g}$ for $15 \mathrm{~min}$. The extracted solutions were then frozen prior to analysis of total and inorganic speciation of ${ }^{127} \mathrm{I}$ and ${ }^{129} \mathrm{I}$ by triple quadrupole inductively coupled plasma mass spectrometry (ICP-QQQ-MS) and high-performance liquid chromatography (HPLC)-ICP-QQQ-MS. The osmolality of each extraction was determined using a $15 \mu \mathrm{l}$ aliquot on a freezing point osmometer (Osmomat 030, Gonotec $\mathrm{GmbH}$, Berlin, Germany). The plants were grown, harvested and treated between May and August 2017.

Iodine storage in plants

Spinach seeds were germinated in starter trays filled with moist perlite. At 28 DAP, individual seedlings were transplanted into an inert growth medium, perlite, in 21 pots. At 38 and 48 DAP, treatment solutions were applied as either ${ }^{127} \mathrm{I}^{-}$or ${ }^{127} \mathrm{IO}_{3}{ }^{-}$at 0 (control), 200 (low) and 2000 (high) $\mu \mathrm{g}^{-1}$ : each treatment had five replicates. At 58 DAP plants were removed from their pots, rinsed with DI water to remove excess perlite, dissected into (i) roots, (ii) stems and (iii) leaves, washed three times in Milli-Q water and blotted dry. The plant components were then frozen, freeze-dried and ground to a fine powder prior to extraction for analysis of total ${ }^{127} \mathrm{I}$ by inductively coupled plasma mass spectrometry (ICPMS). The plants were grown, treated and harvested between May and July 2016.

Iodine translocation from older to younger leaves in spinach

Spinach seeds were germinated and grown in cell seedling starter trays filled with sand. At 32 DAP, one of the first true leaves was tagged and wetted with a treatment solution containing ${ }^{129} \mathrm{I}^{-}$at $200 \mu \mathrm{g} \mathrm{l}^{-1}$ and $0.02 \%$ of a non-ionic surfactant (Silwet L-77), and this treatment was repeated four times over two 
consecutive days: each treatment had three replicates (five plants constituted one replicate). Once treated, the plants were watered daily, carefully avoiding any contact with the leaves. Plants were harvested at 1, 3, 6 and 9 days after the final treatment and dissected into (i) treated first true leaf and (ii) new leaves, then triplewashed in Milli-Q water and blotted dry. The plant components were then frozen, freeze-dried and ground to a fine powder for analysis of total ${ }^{129}$ I by ICP-QQQMS. The plants were grown, treated and harvested between February and March 2018.

Iodine extraction from solid material

Total ${ }^{127} \mathrm{I}$ and ${ }^{129} \mathrm{I}$ was extracted from vegetation samples using the method described by Watts and Mitchell (2009). Finely powdered freeze-dried samples were weighed $(0.25 \mathrm{~g})$ directly into a $15-\mathrm{ml}$ poly(tetrafluoroethene) Nalgene bottle, and $5 \mathrm{ml}$ of $5 \%$ tetramethylammonium hydroxide (TMAH) solution was added. The sample bottles, with lids loosened, were placed in a drying oven at $70{ }^{\circ} \mathrm{C}$ for $3 \mathrm{~h}$ and shaken after $1.5 \mathrm{~h}$. Once cooled, $5 \mathrm{ml}$ of Milli-Q water was added and the bottles were centrifuged at $3500 \mathrm{rpm}$ for $20 \mathrm{~min}$; then, the supernatant was removed for analysis. In addition, a certified reference material (SRM1570a: trace elements in spinach leaves) was extracted and used to validate the results with comparable values to those reported in Watts et al. (2015).

Total ${ }^{127} \mathrm{I}$ and ${ }^{129} \mathrm{I}$ analysis (ICP-QQQ-MS)

Iodine isotopes were assayed by ICP-QQQ-MS (Agilent 8900, Agilent Technologies) featuring a reaction cell situated between two quadrupole mass filters. Total ${ }^{127}$ I concentrations were determined in 'singleMS, no-gas' mode. Total ${ }^{129} \mathrm{I}$ analysis utilised both quadrupoles and the reaction cell of the ICP-QQQMS. The first quadrupole (Q1) mass filter was set to allow only ions of $\mathrm{m} / \mathrm{z}=129$ (target analyte) and $\mathrm{m} /$ $z=125$ (internal standard) to pass through to an $\mathrm{O}_{2}$ reaction cell where the most significant isobaric interference, ${ }^{129} \mathrm{Xe}^{+}$in the argon plasma gas, was removed via a charge transfer reaction: ${ }^{129} \mathrm{Xe}^{+}+\mathrm{O}_{2} \rightarrow{ }^{129} \mathrm{Xe}+\mathrm{O}_{2}{ }^{+}$. It is possible to remove the ${ }^{129} \mathrm{Xe}^{+}$interference with $\mathrm{O}_{2}$ and not influence the ${ }^{129} \mathrm{I}^{+}$detection as this charge transfer reacts at least $10^{4}$ times faster than $\mathrm{O}_{2}$ with ${ }^{129} \mathrm{I}^{+}$
(Izmer et al. 2003). Polyatomic interferences, such as ${ }^{127} \mathrm{IH}_{2}{ }^{+}$, that could be created within the reaction cell were eliminated as ${ }^{127} \mathrm{I}^{+}$was not allowed to enter the reaction cell when $\mathrm{Q} 1$ was set at $m / z=129$ and 125 (Balcaen et al. 2015). The second quadrupole (Q2) mass filter was set to reject all ions except the target analyte mass $(\mathrm{m} / \mathrm{z}=129$ and 125$)$ so that the MS measured only ${ }^{129} \mathrm{I}^{+}$and the internal standard after the interferences had been removed. All samples were diluted with $0.5 \%$ TMAH, and a calibration curve for iodine was prepared with concentrations of $0.5,1,10$, 50 and $100 \mu \mathrm{g} \mathrm{l}^{-1}$ for ${ }^{127} \mathrm{I}$ and $0.5,1,5,10,50 \mu \mathrm{g}^{-1}$ for ${ }^{129}$ I. The LOD (3SD blanks) was $0.13 \mu \mathrm{g} \mathrm{l^{-1 }}$ for ${ }^{127} \mathrm{I}$ and $0.09 \mu \mathrm{g} \mathrm{l}^{-1}$ for ${ }^{129} \mathrm{I}$ analysis in solution. An internal standard of tellurium $(m / z=125)$ in $0.5 \%$ TMAH was mixed with the sample solution via a T-piece to monitor instrument stability.

Inorganic speciation: ${ }^{127} \mathrm{I}$ and ${ }^{129} \mathrm{I}$ analysis ((HPLC)-ICP-QQQ-MS)

The inorganic iodine species, ${ }^{127} \mathrm{I}^{-},{ }^{127} \mathrm{IO}_{3}{ }^{-},{ }^{129} \mathrm{I}^{-}$and ${ }^{129} \mathrm{IO}_{3}{ }^{-}$, were analysed using (HPLC)-ICP-QQQ-MS incorporating an Agilent 1290 Infinity LC System coupled to the Agilent 8900 QQQ-ICP-MS. Samples $(50 \mu \mathrm{l})$ were injected onto an anion exchange column (Hamilton PRP X-100, $250 \mathrm{~mm} \times 4.6 \mathrm{~mm}, 5 \mu \mathrm{m}$ ); the chromatography mobile phase was $100 \mathrm{mM}$ $\mathrm{NH}_{4} \mathrm{NO}_{3}$, adjusted to $\mathrm{pH} 9.5$ with TMAH (25\%) and delivered to the ICP-MS nebuliser at a flow rate of $1.5 \mathrm{ml} \mathrm{min}{ }^{-1}$. Analysis was as described for total ${ }^{129} \mathrm{I}$; LOD values were $0.13,0.22,0.01$ and $0.07 \mu \mathrm{g} \mathrm{l}^{-1}$ for ${ }^{127} \mathrm{I}^{-},{ }^{127} \mathrm{IO}_{3}{ }^{-},{ }^{129} \mathrm{I}^{-}$and ${ }^{129} \mathrm{IO}_{3}{ }^{-}$, respectively.

Total ${ }^{127}$ I analysis (ICP-MS)

Total ${ }^{127}$ I concentrations were determined by ICP-MS (Agilent, model $7500 \mathrm{cx}$ ), with the collision cell in 'nogas' mode. Calibration standards for iodine were 0.5 , $1,10,50$ and $100 \mu \mathrm{g}^{-1}$. The LOD was $0.05 \mathrm{mg} \mathrm{kg}^{-1}$ in solid material. The internal standard was $\mathrm{Te}(\mathrm{m} /$ $\mathrm{z}=125$ ) in $0.5 \%$ TMAH.

Statistical analysis

Statistical analysis was performed in $\mathrm{R}$ version 3.3.3. Significant differences were assessed with either Student's $t$ test or one-way analysis of variance (ANOVA) followed by Tukey HSD post hoc test. 
Differences were considered statistically significant when $P<0.05$. All treatments had a minimum of three replicates, with all results presented as the mean \pm standard deviation (SD).

\section{Results}

Iodine uptake mechanisms: validation of apoplastic and symplastic extraction

To determine whether the apoplastic solution was contaminated with cytoplasmic fluid during the extraction, the osmolality of the isolated apoplastic solutions was compared to that of the bulk solution recovered from freeze-thaw extracted symplast. Osmolality measurements of the apoplastic and symplastic extractions are shown in Fig. 1. The average osmolality in the apoplastic solution was $169 \mathrm{mOsmol}$ $\mathrm{kg}^{-1}$, approximately one-third of the freeze-thaw extracted symplastic solution, which coincides with the existing literature (Yu et al. 1999; Almeida and Huber 1999; Zhang et al. 1996; Husted and

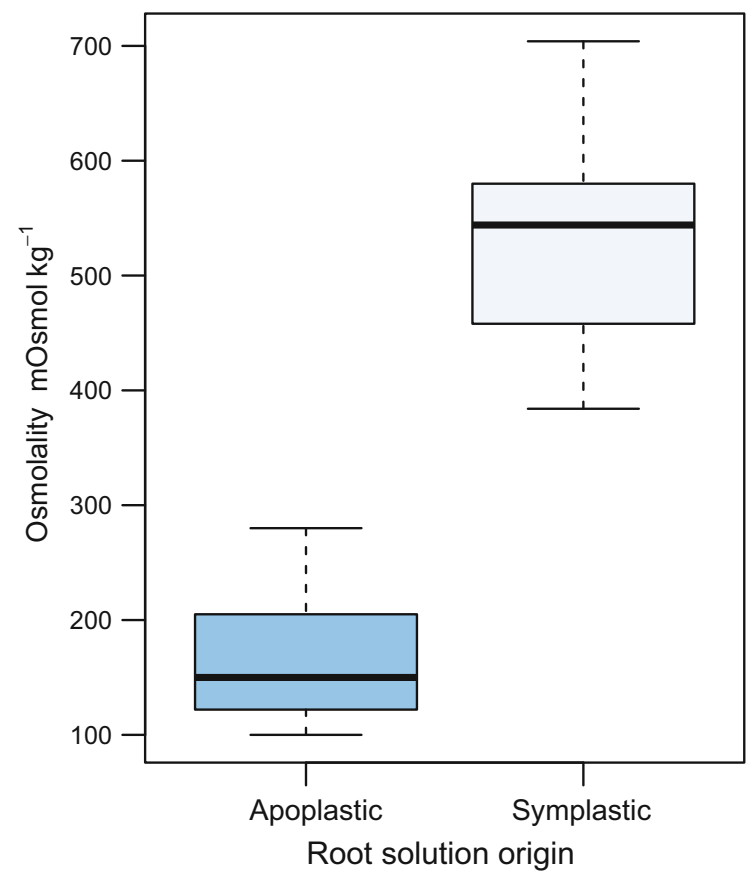

Fig. 1 Osmolality (mOsmol kg-1) of apoplastic and symplastic extracts from root solutions. The bold lines in the boxes represent the median position, whilst the upper and lower limits of the box are the 25 th and 75 th quartile. The vertical lines show the data range
Schjoerring 1995). In addition, a paired t-test confirmed that the solutions were significantly different $(P<0.001)$. Subsequently, it can be assumed that there is limited cytoplasmic contamination in the apoplastic extraction and that these solutions accurately represent the apoplastic and symplastic pathways.

Iodine uptake mechanisms: Effect of incubation on speciation within the treatment solution

To investigate whether changes in speciation of the treatment solution occurred during the experiment, possibly as a result of an interaction with root exudates, total iodine concentrations and the inorganic species of both ${ }^{127} \mathrm{I}$ and ${ }^{129} \mathrm{I}$ were measured in the treatment solution before and after incubation. Iodine concentrations before and after the 24-h incubation period, in the absence and presence of the metabolic inhibitor CCCP, are shown in Fig. 2. It is clear that the total concentration of iodine present in solution decreased throughout the 24-h treatment period as it was absorbed by the plant, with greater uptake occurring in the plants without the metabolic inhibitor. There is also strong evidence to suggest that ${ }^{127} \mathrm{IO}_{3}{ }^{-}$ was being converted to ${ }^{127} \mathrm{I}^{-}$in the treatment solution, at both the low and high treatments, in the absence and presence of the metabolic inhibitor (Fig. 2a, b). Conversely, there was no evidence of any conversion from ${ }^{129} \mathrm{I}^{-}$to ${ }^{129} \mathrm{IO}_{3}{ }^{-}$in any of the treatment solutions (Fig. 2c, d).

Iodine uptake mechanisms

To investigate iodine uptake mechanisms by spinach, the total and inorganic $\left(\mathrm{IO}_{3}{ }^{-}\right.$and $\left.\mathrm{I}^{-}\right)$iodine concentrations were directly measured in apoplastic and symplastic solutions extracted from spinach roots; the organic iodine fraction (org-I) was then calculated by difference (total-inorganic). The total, inorganic and organic iodine concentrations found in the apoplast and symplast extracted in the absence and presence of the metabolic inhibitor CCCP are shown in Fig. 3, respectively. Iodine was present in both the apoplast and symplast, confirming the coexistence of both active and passive uptake pathways. In general, the uptake of $\mathrm{I}^{-}$was marginally greater than that of $\mathrm{IO}_{3}{ }^{-}$, in the absence of the inhibitor. On average, the metabolic inhibitor CCCP inhibited the uptake of 

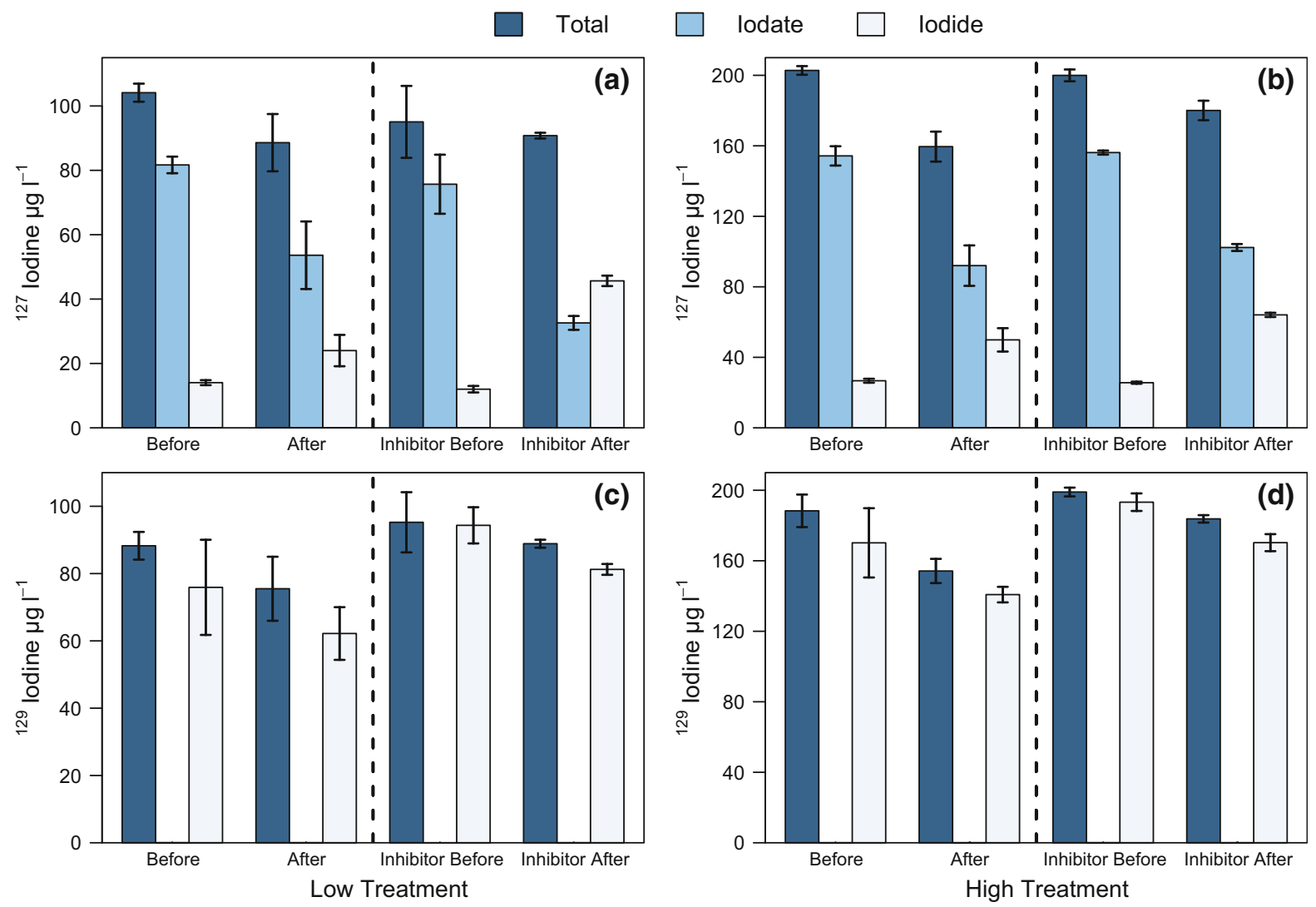

Fig. 2 Total iodine concentration and inorganic speciation in treatment solutions, containing ${ }^{129} \mathrm{I}^{-}$and ${ }^{127} \mathrm{IO}_{3}{ }^{-}$at either 100 or $200 \mu \mathrm{g} \mathrm{l}^{-1}$, before and after the 24 -h treatment period, in the absence and presence of the metabolic inhibitor CCCP. Values

iodine through the root by $30 \%$, with the inhibitor having a greater impact on the uptake of $\mathrm{IO}_{3}{ }^{-}$ compared to $\mathrm{I}^{-}$. Within the apoplastic solution, over $90 \%$ of the iodine present was found as org-I, and the remaining iodine was identified as $\mathrm{I}^{-}$. This suggests that a rapid conversion from inorganic iodine to org-I takes place following absorption by roots. In the presence of the inhibitor, significantly $(P<0.05)$ higher concentrations of $\mathrm{I}^{-}$were found in the apoplast compared to root solutions extracted without the inhibitor. This suggests that the inhibitor impeded the plants ability to convert $\mathrm{I}^{-}$to org-I in the apoplast. Within the symplastic root solution, the concentration of $\mathrm{I}^{-}$was significantly higher $(P<0.01)$ than that of org-I both with and without the metabolic inhibitor; this suggests the plants actively assimilated $\mathrm{I}^{-}$via specific or aspecific pathways. Org-I was also present in the symplastic solution: the total concentration of iodine present in the symplastic solution increased

are given as the mean $\pm \mathrm{SD}(n=3)$. a Iodate low concentration treatment, $\mathbf{b}$ iodate high concentration treatment, $\mathbf{c}$ iodide low concentration treatment, $\mathbf{d}$ iodide high concentration treatment

with the higher treatment concentration and significantly decreased $(P<0.01)$ as a result of exposure to the inhibitor.

Iodine storage in spinach plants

The total concentration of iodine present in the individual plant components applied as either ${ }^{127} \mathrm{I}^{-}$ or ${ }^{127} \mathrm{IO}_{3}{ }^{-}$at 0 (control), 200 (low) or 2000 (high) $\mu \mathrm{g} \mathrm{l^{-1 }}$ is shown in Fig. 4. Plant tissue iodine concentrations were measured on a dry weight (DW) basis; however, since spinach is typically consumed fresh, the results were converted to fresh weight (FW) concentrations based on an average water content of $91.4 \%$. The total concentration of iodine present in the plants significantly increased $(P<0.001)$ between the low and high treatments. There was no significant difference between the uptake and storage of ${ }^{127} \mathrm{I}^{-}$or ${ }^{127} \mathrm{IO}_{3}{ }^{-}$at either iodine concentration. At the highest 


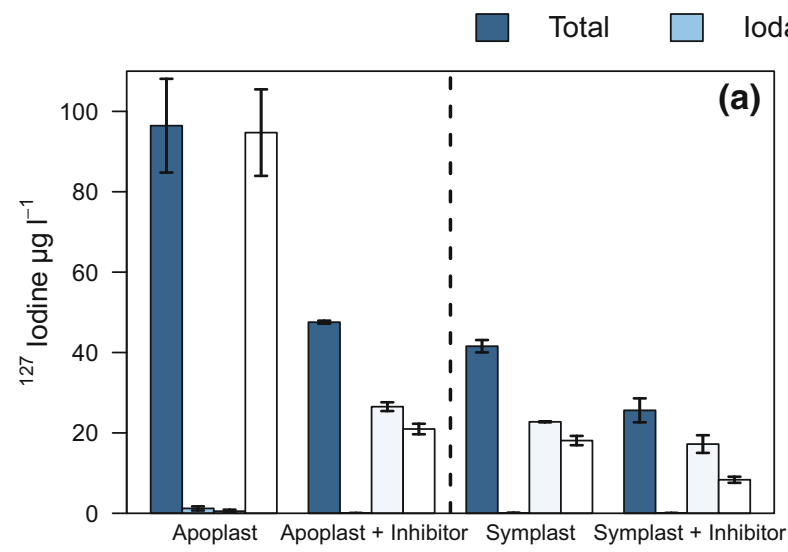

odate $\square \quad$ lodide $\square \quad$ Organic lodine
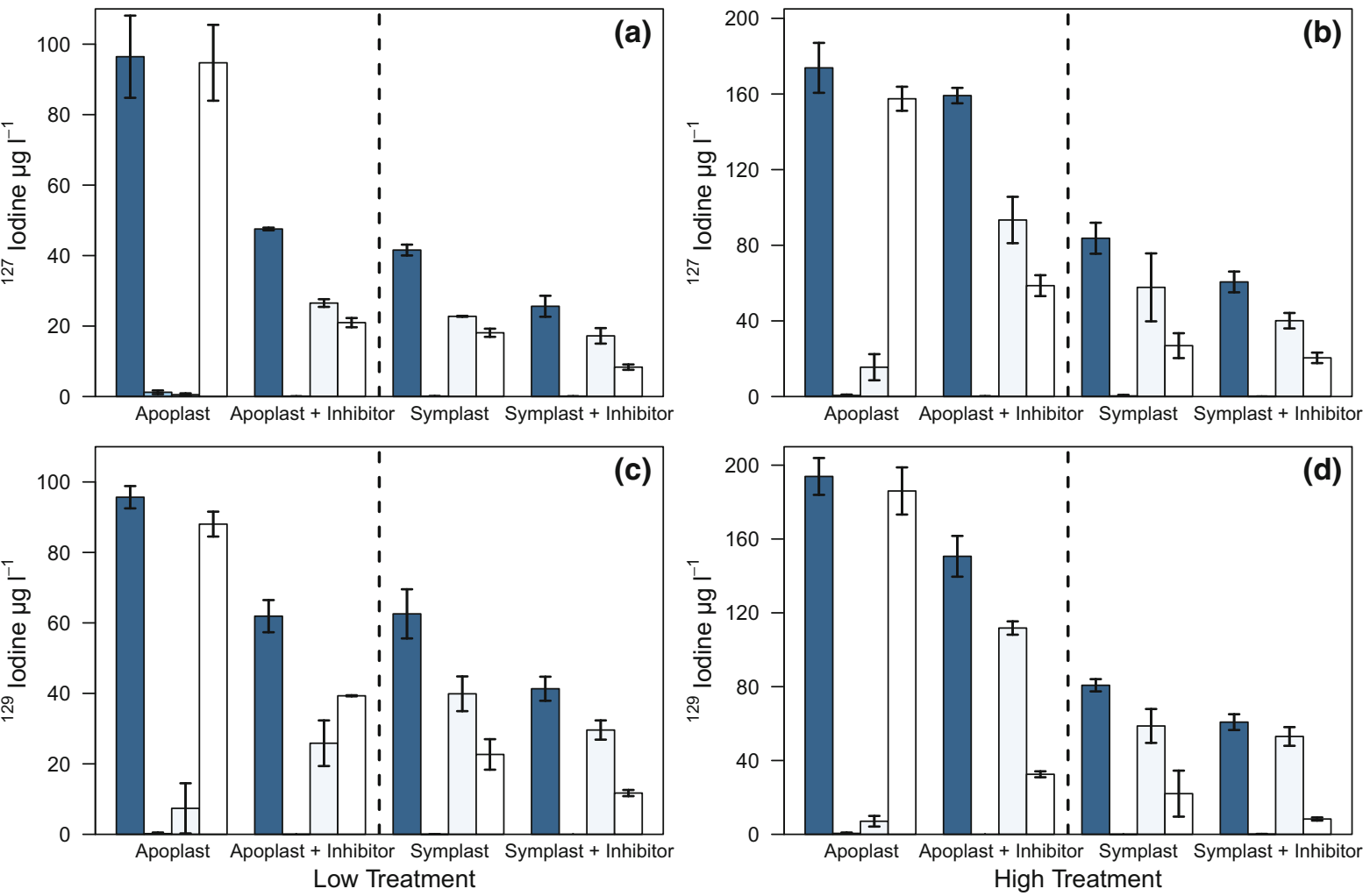

Fig. 3 Total iodine concentration and speciation of iodine present in the apoplastic and symplastic solutions with and without the metabolic inhibitor CCCP. Values are given as the

treatment concentration, iodine concentration in the plant components was found to be in the order: leaves $>$ roots $>$ stems, whereas at the low treatment concentration the order was: roots $>$ leaves $>$ stems. In general, there was good replicate agreement with iodine present in all of the harvested components.

Iodine translocation from older to younger leaves in spinach

This short-term experiment was used to evaluate the degree to which iodine is potentially phloem mobile. The total concentration of ${ }^{129} \mathrm{I}$ present in individually harvested plant components is shown in Table 1. Evidently, iodine was absorbed by the treated leaves; however, iodine phloem mobility appears very limited, as $<2 \%$ of the ${ }^{129} \mathrm{I}^{-}$applied to the treated leaf was transported and identified in younger plant tissue over the duration of the experiment.

mean $\pm \mathrm{SD}(n=3)$. a Iodate low concentration treatment, b iodate high concentration treatment, $\mathbf{c}$ iodide low concentration treatment, $\mathbf{d}$ iodide high concentration treatment

\section{Discussion}

Iodine uptake: root tip interactions

Borst-Pauwels (1961) indicated that $\mathrm{IO}_{3}{ }^{-}$had a more favourable effect on plant growth compared to $\mathrm{I}^{-}$, especially in immature plants, because a slower uptake rate reduced the risk of phytotoxicity. It has been shown that $\mathrm{IO}_{3}{ }^{-}$is reduced to $\mathrm{I}^{-}$, prior to uptake by plant roots (Umaly and Poel 1971; Whitehead 1973; Zhu et al. 2003; Caffagni et al. 2011; Kato et al. 2013), and the slower uptake of $\mathrm{IO}_{3}{ }^{-}$is likely to be associated with the reduction to of $\mathrm{IO}_{3}{ }^{-}$to $\mathrm{I}^{-}$. In this investigation there was a clear conversion from $\mathrm{IO}_{3}{ }^{-}$to $\mathrm{I}^{-}$at both treatment levels during the 24-h incubation period (Fig. 2a, b). Kato et al. (2013) investigated the effect of Oryza sativa L., Hordeum vulgare L. cv. 'Mikamogolden' and Glycine max cv. 'Tachinagaha' roots on the speciation of $\mathrm{I}^{-}$and $\mathrm{IO}_{3}{ }^{-}$in treatment 


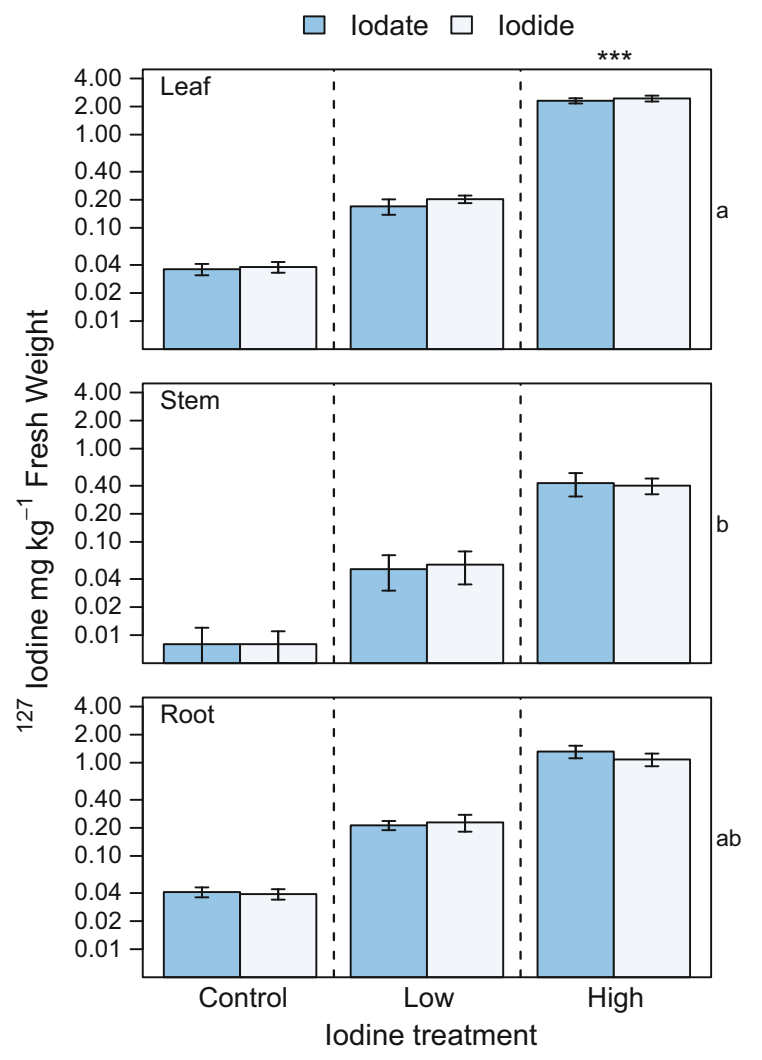

Fig. 4 Total iodine (mg kg ${ }^{-1}$ fresh weight) distribution in spinach (Spinacia oleracea L.), applied as either ${ }^{127} \mathrm{I}^{-}$or ${ }^{127} \mathrm{IO}_{3}{ }^{-}$at concentrations of 0 (control), 200 (low) or 2000 (high) $\mu \mathrm{g}^{-1}$. Y-axis shown on $\log (10)$ scale. Values are the mean $\pm \mathrm{SD}(n=5)$. Tukey HSD post hoc test was used to assess whether the treatments significantly differed from the controls: $* * * P<0.001$. Plant components with significantly different concentrations have different letters $(P<0.01)$

solutions reporting that roots of Oryza sativa L. show iodate reduction activity in response to $\mathrm{IO}_{3}{ }^{-}$, and $100 \%$ of $\mathrm{IO}_{3}{ }^{-}$was converted to $\mathrm{I}^{-}$within $24 \mathrm{~h}$; results in the present study showed that the conversion efficiency for spinach was approximately $30 \%$ (Fig. 2). This suggests that rice and leafy vegetables may have different reduction and iodine uptake mechanisms. Based on the results of the present study (Fig. 2) and the work of Kato et al. (2013), it is evident that plant roots are capable of reducing $\mathrm{IO}_{3}{ }^{-}$to $\mathrm{I}^{-}$in solution.

Iodine uptake mechanisms

It has been suggested that iodine uptake by plant roots could follow apoplastic and symplastic routes into xylem vessels (Gonzali et al. 2017). This hypothesis is supported by the results of the present study. To investigate uptake mechanisms, apoplastic and symplastic solutions were extracted in the absence and presence of a metabolic inhibitor. The results (Fig. 3) showed that uptake of $\mathrm{I}^{-}$was greater than $\mathrm{IO}_{3}{ }^{-}$and that iodine was taken up through both the apoplast and symplast, but it is only found within the plant as $\mathrm{I}^{-}$or org-I.

The concentrations of iodine present in the apoplastic and symplastic solutions suggest that iodine is predominately taken up from solution passively through the apoplast. The average concentration of iodine in the symplastic solution was $<50 \%$ of the concentration present in the apoplastic solution in treatments without the metabolic inhibitor. Weng et al. (2008) performed a similar experiment investigating the uptake mechanisms of iodine in Brassica chinensis L.; they found that the metabolic inhibitor 2,4dinitrophenol had a greater impact at lower concentrations of iodine. The results in the present study show that the uptake of iodine in both the apoplast and symplast was significantly more sensitive to the metabolic inhibitor at the lower concentration, particularly for the $\mathrm{IO}_{3}{ }^{-}$treatment $(P<0.01)$; these results are in agreement with Weng et al. (2008). At the higher treatment concentration of both $\mathrm{I}^{-}$and $\mathrm{IO}_{3}{ }^{-}$, the amount of iodine present in the apoplast was proportionately greater than in the lower concentration

Table 1 Concentration $\left({ }^{129} \mathrm{I} \mu \mathrm{g} \mathrm{kg}^{-1}\right.$ fresh weight) of iodine present in treated and new leaves 1, 3, 6 and 9 days after treatment. Values are the mean $\pm \mathrm{SD}(n=3)$. Detection limit ${ }^{129} \mathrm{I}=0.1 \mu \mathrm{g} \mathrm{kg}^{-1}$ fresh weight in solid material

Total ${ }^{129} \mathrm{I} \mu \mathrm{g} \mathrm{kg}^{-1} \mathrm{FW}$

\begin{tabular}{lllll}
\hline & Day 1 & Day 3 & Day 6 & Day 9 \\
\hline Treated leaf & $12.02 \pm 4.66$ & $7.19 \pm 1.40$ & $10.06 \pm 2.27$ & $9.88 \pm 3.36$ \\
Younger leaves & $0.11 \pm 0.03$ & $0.13 \pm 0.09$ & $0.19 \pm 0.10$ & $0.14 \pm 0.10$ \\
Translocation to younger leaves $(\%)$ & $0.91 \%$ & $1.78 \%$ & $1.85 \%$ & $1.40 \%$ \\
\hline
\end{tabular}


treatment in the presence of the inhibitor. Thus, as the concentration of iodine in solution increased, the uptake mechanism became dominated by the passive (apoplastic) pathway, potentially due to the saturation of active transport sites.

In apoplastic solutions without the inhibitor present, iodine was almost entirely org-I. However, in apoplastic solution extracted from roots incubated with the inhibitor, there were significantly higher concentrations of $\mathrm{I}^{-}$with a concomitant decrease in org-I. This suggests that the conversion to org-I occurs in the root system. The symplastic extraction confirms that spinach roots can absorb iodine through active pathways. Whilst the total concentration of iodine in the symplast was lower than in the apoplast, more $\mathrm{I}^{-}$ was observed than org-I, indicating that $\mathrm{I}^{-}$is being taken up by either specific or aspecific pathways which limit conversion of $\mathrm{I}^{-}$to org-I.

Based on the hypothesis proposed by Gonzali et al. (2017), and the results of the present study, it is clear that the transport of iodine occurs passively and actively through transporters and channels. Chloride $\left(\mathrm{Cl}^{-}\right)$channels, $\mathrm{Na}^{+}: \mathrm{K}^{+} / \mathrm{Cl}^{-}$co-transporters, $\mathrm{H}^{+} / \mathrm{Cl}^{-}$ symporters or antiporters, and $\mathrm{Cl}^{-}$transporters energised by ATP-dependent proton pumps are likely to be involved in iodine transport considering similarities between chloride and iodide ions (Gonzali et al. 2017; Smoleń et al. 2014; White and Broadley 2001; Roberts 2006). The reduction in iodine uptake in the presence of the metabolic inhibitor CCCP is likely to be associated with the impact of CCCP on the ATPdependent proton pumps.

Iodine storage in spinach

Phytofortification is a means of increasing dietary iodine consumption; however, its effectiveness would be limited if crops were unable to store substantial concentrations in the edible components. When iodine was taken up by the roots (high treatment concentration), spinach was capable of storing $>60 \%$ of the absorbed iodine in the above-ground edible biomass, confirming that iodine is transported via the xylem (Fig. 4). The transfer of iodine through the xylem and accumulation in leaves has been previously demonstrated in a range of crops (Blasco et al. 2008; Voogt et al. 2010; Dai et al. 2006).

Whilst there were no significant differences in uptake and storage of $\mathrm{I}^{-}$and $\mathrm{IO}_{3}{ }^{-}$(Fig. 4) during the course of this experiment, several authors have demonstrated greater $\mathrm{I}^{-}$uptake in solution or nonsoil substrates compared to $\mathrm{IO}_{3}{ }^{-}$in other short-term experiments (Zhu et al. 2003; Mackowiak and Grossl 1999; Caffagni et al. 2011; Whitehead 1973; Voogt et al. 2010; Borst-Pauwels 1961). However, when iodine is applied to soils, $\mathrm{IO}_{3}{ }^{-}$treatments are utilised by plants to a much greater extent than $\mathrm{I}^{-}$(Dai et al. 2006; Lawson et al. 2015; Hong et al. 2012; MedranoMacias et al. 2016). The discrepancy between iodine uptake from soils and solution is probably associated with changes in availability resulting from reaction with soil constituents. When inorganic iodine is added to soils as $\mathrm{I}^{-}$or $\mathrm{IO}_{3}{ }^{-}$, a conversion from inorganic to less available organically bound species occurs within minutes to days and days to weeks, respectively (Yamaguchi et al. 2010; Shimamoto et al. 2011; Schwehr et al. 2009; Shetaya et al. 2012; Bowley et al. 2016). Rapid conversion of $\mathrm{I}^{-}$to org-I would limit the ability of plants to absorb applied $\mathrm{I}^{-}$, whilst applications of $\mathrm{IO}_{3}{ }^{-}$would remain available for plant uptake for longer.

Iodine translocation to younger leaves

Foliar fertilisation is a convenient method of fortifying crops with micronutrients (Fernandez and Brown 2013). The findings of the current study support previous work (Blasco et al. 2008; Cakmak et al. 2017; Lawson et al. 2015) which demonstrated that iodide is suitable for foliar fertilisation, as it was absorbed and stored in the treated leaves (Table 1). Throughout the experiment, individually treated leaves had an average concentration of $9.8 \mu \mathrm{g} \mathrm{kg}^{-1}\left({ }^{129} \mathrm{I}\right)$, highlighting that leaves are capable of absorbing and retaining iodine applied directly to foliage. Shaw et al. (2007) previously reported that when $\mathrm{I}^{-}$was applied to the foliar surface of Vicia faba L., it was mostly fixed by the leaves in the cuticular waxes, and it is likely that this same fixation process occurred in the treated spinach leaves in the present study. Iodine is not anticipated to be particularly mobile through the phloem due to its non-essential role in plant development and organophilic nature (Voogt et al. 2010; Herrett et al. 1962; Mackowiak and Grossl 1999; Muramatsu and Yoshida 1995; Hurtevent et al. 2013). Concentrations of ${ }^{129} \mathrm{I}$ measured in individual plant components at 1, 3, 6 and 9 days after treatment provide evidence that ${ }^{129} \mathrm{I}$ applied was only marginally phloem mobile. 
Hurtevent et al. (2013) reported the translocation factor for ${ }^{125} \mathrm{I}^{-}$ranged from 0.02 to $1.1 \%$ over a $24-\mathrm{h}$ treatment period in wheat, similar to the translocation observed in this work for spinach leaves harvested 1 day after foliage treatment (Table 1). In this study, over 9 days, $<2 \%$ of the total ${ }^{129}$ I applied to the plant was transported to younger leaves, suggesting that the majority had been fixed within the leaves. Using ${ }^{129} \mathrm{I}$ as a tracer to demonstrate that iodine applied to foliage has minimal translocation potential has greater certainty compared to studies using ${ }^{127}$ I (Cakmak et al. 2017; Smoleń et al. 2014; Li et al. 2017) because it allows unequivocal discrimination between phloem and xylem transfer.

\section{Conclusions}

In solution, $\mathrm{I}^{-}$has greater availability to spinach plants than $\mathrm{IO}_{3}{ }^{-}$, and roots have the ability to reduce $\mathrm{IO}_{3}{ }^{-}$to $\mathrm{I}^{-}$. Iodine uptake can occur actively (approximately one-third of total uptake), through the symplast; however, sorption of iodine is predominately passive (approximately two-thirds of total uptake), with higher concentrations observed in the apoplastic solution. There were no significant differences between the uptake of $\mathrm{IO}_{3}{ }^{-}$or $\mathrm{I}^{-}$from an inert growth substrate, with the majority of iodine being stored in the aboveground biomass of spinach. Finally, foliar fertilisation with ${ }^{129} \mathrm{I}^{-}$was shown to be a successful means of increasing the concentration of iodine in plant leaves. Phloem mobility of iodine was shown to be severely limited, and therefore, only leaves contacted directly by foliar spraying would have enhanced iodine concentrations. Furthermore, foliar application is unlikely to significantly increase the iodine content, via phloem translocation, of fruits, grains or tubers.

\footnotetext{
Acknowledgements Funding for O. S. Humphrey was provided by the British Geological Survey-University of Nottingham, Centre for Environmental Geochemistry, BGS University Funding Initiative (contract number: BUFI-S314). The authors would like to thank Mark Meecham and the Sutton Bonington glasshouse staff for assistance with growing the plants and David Gardner for assistance with osmolality measurements. Special thanks to BGS laboratory staff with sample preparation and analysis and to Dr Louise Ander for initial comments for the overall study. This work is published with the permission of the Executive Director, British Geological Survey.
}

Author contribution All authors contributed to this work. O.S.H, S.D.Y, E.H.B, N.M.J.C and M.J.W conceived the ideas and designed the research; O.S.H and E.M.H performed the experiments and analysed the data; O.S.H wrote the manuscript with feedback from all co-authors.

\section{Compliance with ethical standards}

Conflict of interest The authors declare that they have no conflict of interest.

\section{References}

Almeida, D. P. F., \& Huber, D. J. (1999). Apoplastic pH and inorganic ion levels in tomato fruit: A potential means for regulation of cell wall metabolism during ripening. Physiologia Plantarum, 105(3), 506-512. https://doi.org/10. 1034/j.1399-3054.1999.105316.x.

Altınok, S., Sozudogru-Ok, S., \& Halilova, H. (2003). Effect of iodine treatments on forage yields of Alfalfa. Communications in Soil Science and Plant Analysis, 34(1-2), 55-64. https://doi.org/10.1081/CSS-120017415.

Andersson, M., Karumbunathan, V., \& Zimmermann, M. B. (2012). Global iodine status in 2011 and trends over the past decade. The Journal of Nutrition, 142(4), 744-750. https://doi.org/10.3945/jn.111.149393.

Balcaen, L., Bolea-Fernandez, E., Resano, M., \& Vanhaecke, F. (2015). Inductively coupled plasma-Tandem mass spectrometry (ICP-MS/MS): A powerful and universal tool for the interference-free determination of (ultra)trace elements-A tutorial review. Analytica Chimica Acta, 894, 7-19. https://doi.org/10.1016/j.aca.2015.08.053.

Blasco, B., Rios, J. J., Cervilla, L. M., Sánchez-Rodrigez, E., Ruiz, J. M., \& Romero, L. (2008). Iodine biofortification and antioxidant capacity of lettuce: potential benefits for cultivation and human health. Annals of Applied Biology, 152(3), 289-299. https://doi.org/10.1111/j.1744-7348. 2008.00217.x.

Borst-Pauwels, G. W. F. H. (1961). Iodine as a micronutrient for plants. [journal article]. Plant and Soil, 14(4), 377-392. https://doi.org/10.1007/bf01666295.

Bowley, H. E., Young, S. D., Ander, E. L., Crout, N. M. J., Watts, M. J., \& Bailey, E. H. (2016). Iodine binding to humic acid. Chemosphere, 157, 208-214. https://doi.org/ 10.1016/j.chemosphere.2016.05.028.

Caffagni, A., Arru, L., Meriggi, P., Milc, J., Perata, P., \& Pecchioni, N. (2011). Iodine fortification plant screening process and accumulation in tomato fruits and potato tubers. Communications in Soil Science and Plant Analysis, 42(6), 706-718. https://doi.org/10.1080/00103624. 2011.550372.

Cakmak, I., Prom-u-thai, C., Guilherme, L. R. G., Rashid, A., Hora, K. H., Yazici, A., et al. (2017). Iodine biofortification of wheat, rice and maize through fertilizer strategy. Plant and Soil, 418(1-2), 319-335.

Dai, J. L., Zhu, Y. G., Huang, Y. Z., Zhang, M., \& Song, J. L. (2006). Availability of iodide and iodate to spinach (Spinacia oleracea L.) in relation to total iodine in soil 
solution. Plant and Soil, 289(1-2), 301-308. https://doi. org/10.1007/s11104-006-9139-7.

Fernandez, V., \& Brown, P. H. (2013). From plant surface to plant metabolism: the uncertain fate of foliar-applied nutrients. Frontiers in Plant Science, 4(289), 1-5.

Fuge, R., \& Johnson, C. C. (2015). Iodine and human health, the role of environmental geochemistry and diet, a review. Applied Geochemistry, 63, 282-302. https://doi.org/10. 1016/j.apgeochem.2015.09.013.

Gonzali, S., Kiferle, C., \& Perata, P. (2017). Iodine biofortification of crops: agronomic biofortification, metabolic engineering and iodine bioavailability. Current Opinion in Biotechnology, 44, 16-26. https://doi.org/10.1016/j. copbio.2016.10.004.

Herrett, R. A., Hatfield, H. H., Crosby, D. G., \& Vlitos, A. J. (1962). Leaf abscission induced by the iodide ion. Plant Physiology, 37(3), 358-363.

Hong, C., Weng, H., Jilani, G., Yan, A., Liu, H., \& Xue, Z. (2012). Evaluation of iodide and iodate for adsorptiondesorption characteristics and bioavailability in three types of soil. [journal article]. Biological Trace Element Research, 146(2), 262-271. https://doi.org/10.1007/ s12011-011-9231-6.

Hong, C., Weng, H., Yan, A., \& Islam, E. (2009). The fate of exogenous iodine in pot soil cultivated with vegetables. Environmental Geochemistry and Health, 31(1), 99-108. https://doi.org/10.1007/s10653-008-9169-6.

Humphrey, O. S., Young, S. D., Bailey, E. H., Crout, N. M. J., Ander, E. L., \& Watts, M. J. (2018). Iodine soil dynamics and methods of measurement: A review. Environmental Science: Processes \& Impacts, 20(2), 288-310. https://doi. org/10.1039/c7em00491e.

Hurtevent, P., Thiry, Y., Levchuk, S., Yoschenko, V., Henner, P., Madoz-Escande, C., et al. (2013). Translocation of $125 \mathrm{I}, 75 \mathrm{Se}$ and $36 \mathrm{Cl}$ to wheat edible parts following wet foliar contamination under field conditions. Journal of Environmental Radioactivity, 121, 43-54. https://doi.org/ 10.1016/j.jenvrad.2012.04.013.

Husted, S., \& Schjoerring, J. K. (1995). Apoplastic pH and ammonium concentration in leaves of Brassica napus $\mathrm{L}$. Plant Physiology, 109(4), 1453-1460. https://doi.org/10. 1104/pp.109.4.1453.

Ito, M., Ohnishi, Y., Itoh, S., \& Nishimura, M. (1983). Carbonyl cyanide-m-chlorophenyl hydrazone-resistant Escherichia coli mutant that exhibits a temperature-sensitive unc phenotype. Journal of Bacteriology, 153(1), 310-315.

Izmer, A. V., Boulyga, S. F., \& Becker, J. S. (2003). Determination of 129I/127I isotope ratios in liquid solutions and environmental soil samples by ICP-MS with hexapole collision cell. Journal of Analytical Atomic Spectrometry, 18(11), 1339-1345. https://doi.org/10.1039/b306446h.

Kato, S., Wachi, T., Yoshihira, K., Nakagawa, T., Ishikawa, A., Takagi, D., et al. (2013). Rice (Oryza sativa L.) roots have iodate reduction activity in response to iodine. Frontiers in Plant Science, 4, 227. https://doi.org/10.3389/fpls.2013. 00227.

Keppler, F., Biester, H., Putschew, A., Silk, P. J., Schöler, H. F., \& Müller, G. (2003). Organoiodine formation during humification in peatlands. [journal article]. Environmental Chemistry Letters, 1(4), 219-223. https://doi.org/10.1007/ s10311-003-0044-5.
Landini, M., Gonzali, S., \& Perata, P. (2011). Iodine biofortification in tomato. Journal of Plant Nutrition and Soil Science, 174(3), 480-486.

Lawson, P. G., Daum, D., Czauderna, R., Meuser, H., \& Härtling, J. W. (2015). Soil versus foliar iodine fertilization as a biofortification strategy for field-grown vegetables. Frontiers in Plant Science, 6, 450. https://doi.org/10.3389/ fpls.2015.00450.

Li, R., Liu, H. P., Hong, C. L., Dai, Z. X., Lui, J. W., Zhou, J., et al. (2017). Iodide and iodate effects on the growth and fruit quality of strawberry. Journal of the Science of Food and Agriculture, 97(1), 230-235. https://doi.org/10.1002/ jsfa.7719.

Lyons, G. H. (2018). Biofortification of cereals with foliar selenium and iodine could reduce hypothyroidism. Frontiers in Plant Science, 9, 730.

Mackowiak, C. L., \& Grossl, P. R. (1999). Iodate and iodide effects on iodine uptake and partitioning in rice (Oryza sativa L.) grown in solution culture. Plant and Soil, 212(2), 133-141. https://doi.org/10.1023/a:1004666607330.

Medrano-Macias, J., Leija-Martínez, P., González-Morales, S., Juárez-Maldonado, A., \& Benavides-Mendoza, A. (2016). Use of iodine to biofortify and promote growth and stress tolerance in crops. Frontiers in Plant Science, 7, 1146.

Mitani, N., \& Ma, J. F. (2005). Uptake system of silicon in different plant species. Journal of Experimental Botany, 56(414), 1255-1261. https://doi.org/10.1093/jxb/eri121.

Muramatsu, Y., \& Yoshida, S. (1995). Volatilization of methyl iodide from the soil-plant system. Atmospheric Environment, 29(1), 21-25. https://doi.org/10.1016/13522310(94)00220-F.

Roberts, S. K. (2006). Plasma membrane anion channels in higher plants and their putative functions in roots. New Phytologist, 169(4), 647-666.

Schwehr, K. A., Santschi, P. H., Kaplan, D. I., Yeager, C. M., \& Brinkmeyer, R. (2009). Organo-iodine formation in soils and aquifer sediments at ambient concentrations. Environmental Science and Technology, 43(19), 7258-7264. https://doi.org/10.1021/es900795k.

Shaw, G., Scott, L. K., \& Kinnersley, R. P. (2007). Sorption of caesium, iodine and sulphur in solution to the adaxial leaf surface of broad bean (Vicia faba L.). Environmental and Experimental Botany, 59(3), 361-370. https://doi.org/10. 1016/j.envexpbot.2006.04.008.

Shetaya, W., Young, S., Watts, M., Ander, E., \& Bailey, E. (2012). Iodine dynamics in soils. Geochimica et Cosmochimica Acta, 77, 457-473.

Shimamoto, Y. S., Takahashi, Y., \& Terada, Y. (2011). Formation of organic iodine supplied as iodide in a soil-water system in chiba. Japan. Environmental Science \& Technology, 45(6), 2086-2092. https://doi.org/10.1021/ es 1032162 .

Smoleń, S., Kowalska, I., \& Sady, W. (2014). Assessment of biofortification with iodine and selenium of lettuce cultivated in the NFT hydroponic system. Scientia Horticulturae, 166, 9-16.

Tsukada, H., Takeda, A., Tagami, K., \& Uchida, S. (2008). Uptake and distribution of iodine in rice plants all rights reserved. No part of this periodical may be reproduced or transmitted in any form or by any means, electronic or mechanical, including photocopying, recording, or any 
information storage and retrieval system, without permission in writing from the publisher. Journal of Environmental Quality. https://doi.org/10.2134/jeq2008.0010.

Umaly, R. C., \& Poel, L. W. (1971). Effects of lodine in various formulations on the growth of barley and pea plants in nutrient solution culture. Annals of Botany, 35(1), 127-131. https://doi.org/10.1093/oxfordjournals.aob. a084451.

Voogt, W., Holwerda, H. T., \& Khodabaks, R. (2010). Biofortification of lettuce (Lactuca sativa $\mathrm{L}$.) with iodine: The effect of iodine form and concentration in the nutrient solution on growth, development and iodine uptake of lettuce grown in water culture. Journal of the Science of Food and Agriculture, 90(5), 906-913. https://doi.org/10. 1002/jsfa.3902.

Watts, M., Joy, E., Young, S., Broadley, M., Chilimba, A., Gibson, R., et al. (2015). Iodine source apportionment in the Malawian diet. Scientific Reports, 5, 15251.

Watts, M., \& Mitchell, C. (2009). A pilot study on iodine in soils of Greater Kabul and Nangarhar provinces of Afghanistan. Environmental Geochemistry and Health, 31(4), 503-509.

Weng, H.-X., Hong, C.-L., Yan, A.-L., Pan, L.-H., Qin, Y.-C., Bao, L.-T., et al. (2008). Mechanism of Iodine uptake by cabbage: Effects of iodine species and where it is stored. Biological Trace Element Research, 125(1), 59-71. https:// doi.org/10.1007/s12011-008-8155-2.

Weng, H.-X., Yan, A.-L., Hong, C.-L., Qin, Y.-C., Pan, L., \& Xie, L.-L. (2009). Biogeochemical transfer and dynamics of iodine in a soil-plant system. Environmental Geochemistry and Health, 31(3), 401-411. https://doi.org/10. 1007/s10653-008-9193-6.

White, P. J., \& Broadley, M. R. (2001). Chloride in soils and its uptake and movement within the plant: A review. Annals of Botany, 88(6), 967-988. https://doi.org/10.1006/anbo. 2001.1540.

White, P. J., \& Broadley, M. R. (2009). Biofortification of crops with seven mineral elements often lacking in human dietsiron, zinc, copper, calcium, magnesium, selenium and iodine. New Phytologist, 182(1), 49-84.

Whitehead, D. (1973). Uptake and distribution of iodine in grass and clover plants grown in solution culture. Journal of the Science of Food and Agriculture, 24(1), 43-50.

WHO, Unicef, \& ICCIDD. (2007). Assessment of iodine deficiency disorders and monitoring their elimination. Geneva: World Health Organization Press.

Wright, K. M., \& Oparka, K. J. (1997). Metabolic inhibitors induce symplastic movement of solutes from the transport phloem of Arabidopsis roots. Journal of Experimental Botany, 48(10), 1807-1814.

Xu, C., Zhang, S., Ho, Y.-F., Miller, E. J., Roberts, K. A., Li, H.P., et al. (2011). Is soil natural organic matter a sink or source for mobile radioiodine (129I) at the Savannah River site? Geochimica et Cosmochimica Acta, 75(19), 5716-5735. https://doi.org/10.1016/j.gca.2011.07.011.

Yamaguchi, N., Nakano, M., Takamatsu, R., \& Tanida, H. (2010). Inorganic iodine incorporation into soil organic matter: evidence from iodine K-edge X-ray absorption near-edge structure. Journal of Environmental Radioactivity, 101(6), 451-457. https://doi.org/10.1016/j.jenvrad. 2008.06.003.

Yang, H., Liu, W., Li, B., Zhang, H., Liu, X., \& Chen, D. (2007). Speciation analysis for iodine in groundwater using high performance liquid chromatography-inductively coupled plasma-mass spectrometry (HPLC-ICP-MS). Geostandards and Geoanalytical Research, 31(4), 345-351. https://doi.org/10.1111/j.1751-908X.2007.00132.x.

Yu, Q., Tang, C., Chen, Z., \& Kuo, J. (1999). Extraction of apoplastic sap from plant roots by centrifugation. New Phytologist, 143(2), 299-304.

Zhang, W., Atwell, B. J., Patrick, J. W., \& Walker, N. A. (1996). Turgor-dependent efflux of assimilates from coats of developing seed of Phaseolus vulgaris L.: Water relations of the cells involved in efflux. [journal article]. Planta, 199(1), 25-33. https://doi.org/10.1007/bf00196877.

Zhang, L. J., Chen, Z. W., Wang, J. Y., \& Bao, J. M. (2000). Iodine loss from iodized salt during processing, sale and consumption. Zhejiang Journal of Preventive Medicine, 12, 32-34. (in Chinese).

Zhu, Y. G., Huang, Y. Z., Hu, Y., \& Liu, Y. X. (2003). Iodine uptake by spinach (Spinacia oleracea L.) plants grown in solution culture: Effects of iodine species and solution concentrations. Environment International, 29(1), 33-37. https://doi.org/10.1016/S0160-4120(02)00129-0.

Zimmermann, M. B. (2008). Iodine requirements and the risks and benefits of correcting iodine deficiency in populations. Journal of Trace Elements in Medicine and Biology, 22(2), 81-92. https://doi.org/10.1016/j.jtemb.2008.03.001.

Zimmermann, M. B., \& Andersson, M. (2012). Assessment of iodine nutrition in populations: past, present, and future. Nutrition Reviews, 70(10), 553-570. https://doi.org/10. 1111/j.1753-4887.2012.00528.x.

Zimmermann, M. B., Gizak, M., Abbott, K., Andersson, M., \& Lazarus, J. H. (2015). Iodine deficiency in pregnant women in Europe. The Lancet Diabetes \& Endocrinology, 3(9), 672-674. https://doi.org/10.1016/S2213-8587(15)00263-6.

Publisher's Note Springer Nature remains neutral with regard to jurisdictional claims in published maps and institutional affiliations. 